\title{
Article \\ Cell Lysis Directed by SulA in Response to DNA Damage in Escherichia coli
}

\author{
Masayuki Murata ${ }^{1}$, Keiko Nakamura ${ }^{2}$, Tomoyuki Kosaka ${ }^{1,3}$, Natsuko Ota ${ }^{1}$, Ayumi Osawa ${ }^{1}$, Ryunosuke Muro ${ }^{2}$, \\ Kazuya Fujiyama ${ }^{2}$, Taku Oshima ${ }^{4}$, Hirotada Mori ${ }^{5}\left(\mathbb{D}\right.$, Barry L. Wanner 6 and Mamoru Yamada ${ }^{1,2,3, *(D)}$ \\ 1 Life Science, Graduate School of Science and Technology for Innovation, Yamaguchi University, \\ Ube 755-8611, Japan; muratam@yamaguchi-u.ac.jp (M.M.); tkosaka@yamaguchi-u.ac.jp (T.K.); \\ b007vh@yamaguchi-u.ac.jp (N.O.); jyunroma@gmail.com (A.O.) \\ 2 Applied Molecular Bioscience, Graduate School of Medicine, Yamaguchi University, Ube 755-8505, Japan; \\ keiko_nakamura038@yahoo.co.jp (K.N.); muro-im@m.u-tokyo.ac.jp (R.M.); \\ dukes_blaze_soul_ignite@yahoo.co.jp (K.F.) \\ 3 Research Center for Thermotolerant Microbial Resources, Yamaguchi University, Yamaguchi 753-8515, Japan \\ 4 Department of Biotechnology, Toyama Prefectural University, 5180 Kurokawa, Imizu, \\ Toyama 939-0398, Japan; taku@pu-toyama.ac.jp \\ 5 Graduate School of Information Science, Nara Institute of Science and Technology, 8916-5 Takayama, Ikoma, \\ Nara 630-0192, Japan; hirotada.mori@gmail.com \\ 6 Department of Microbiology, Harvard Medical School, Boston, MA 02115, USA; \\ Barry_Wanner@hms.harvard.edu \\ * Correspondence: m-yamada@yamaguchi-u.ac.jp; Tel.: +81-83-933-5869
}

Citation: Murata, M.; Nakamura, K.; Kosaka, T.; Ota, N.; Osawa, A. Muro, R.; Fujiyama, K.; Oshima, T. Mori, H.; Wanner, B.L.; et al. Cell Lysis Directed by SulA in Response to DNA Damage in Escherichia coli. Int. J. Mol. Sci. 2021, 22, 4535. https:// doi.org/10.3390/ijms22094535

Academic Editor: Satish Raina

Received: 15 March 2021

Accepted: 21 April 2021

Published: 26 April 2021

Publisher's Note: MDPI stays neutral with regard to jurisdictional claims in published maps and institutional affiliations.

Copyright: (C) 2021 by the authors. Licensee MDPI, Basel, Switzerland. This article is an open access article distributed under the terms and conditions of the Creative Commons Attribution (CC BY) license (https:// creativecommons.org/licenses/by/ $4.0 /)$
Abstract: The SOS response is induced upon DNA damage and the inhibition of $\mathrm{Z}$ ring formation by the product of the sulA gene, which is one of the LexA-regulated genes, allows time for repair of damaged DNA. On the other hand, severely DNA-damaged cells are eliminated from cell populations. Overexpression of sulA leads to cell lysis, suggesting SulA eliminates cells with unrepaired damaged DNA. Transcriptome analysis revealed that overexpression of sulA leads to up-regulation of numerous genes, including soxS. Deletion of soxS markedly reduced the extent of cell lysis by sulA overexpression and soxS overexpression alone led to cell lysis. Further experiments on the SoxS regulon suggested that $\mathrm{LpxC}$ is a main player downstream from SoxS. These findings suggested the SulA-dependent cell lysis (SDCL) cascade as follows: SulA $\rightarrow$ SoxS $\rightarrow$ LpxC. Other tests showed that the SDCL cascade pathway does not overlap with the apoptosis-like and mazEF cell death pathways.

Keywords: DNA damage; SulA; cell lysis; SoxS; LpxC

\section{Introduction}

DNA damage is harmful to all living organisms. Severe DNA damage leads to the removal of DNA-damaged cells from the cell population. In mammals, DNA damage directs the accumulation of the transcription factor p53, leading to cell cycle arrest or apoptosis. The p53 is stabilized by phosphorylation of its N-terminal in response to DNA damage [1-3], promoting transcription of the gene for the cyclin-dependent kinase inhibitor p21/ WAF1 [4], which inhibits the cyclin CDK2 complex, resulting in cell cycle arrest at G1 [5]. Severe DNA damage leads to a greater degree of p53 phosphorylation [6], leading to up-regulation of proapoptotic genes, such as p53AIP1 [7], which in turn leads to apoptosis.

DNA damage promotes an elaborate SOS response in Escherichia coli [8]. More than 40 genes are negatively controlled by LexA and up-regulated in response to DNA damaging agents [9], which in turn act to repair the damaged DNA [10] or cell death by LexAcontrolled toxin-antitoxin genes [11]. The LexA regulon protein SulA inhibits assembly of FtsZ, an essential factor for cell division [12], arresting cell division and filamentous cell formation. Cell division arrest may supply time for DNA repair by DNA polymerases II, IV, V and other repair proteins [13]. Therefore, SulA may function as a checkpoint 
protein by inhibiting cell division when cells are exposed to DNA-damaging agents [14]. After completion of DNA repair, SulA is degraded by ATP-dependent proteases Lon and HslUV $[15,16]$ and cell division resumes. However, serious defects in DNA's over-repairing capability may lead to the removal of damaged cells by cell death/lysis.

The function of SulA in cell cycle arrest in E. coli is like that of p53 in eukaryotes, but it has not been clearly shown whether SulA or other factors are responsible for the elimination of highly damaged cells. We hypothesized that prolonged accumulation of SulA due to an unrepairable amount of damaged DNA causes cell death/lysis. Consistent with our hypothesis, overproduction of SulA resulted in protein accumulation in the medium, which was close to that of the treatment by a mutagen, mitomycin C (MMC) that is known to evoke an SOS response by introducing DNA damage- $\mathrm{dG}$ adduct of MMC or interstrand cross-linkage in DNA $[17,18]$ — suggesting SulA-dependent cell lysis (SDCL). Further investigation including transcriptome analysis was conducted to find downstream factors in the SulA-dependent cell lysis (SDCL) cascade.

\section{Results}

\subsection{Induction of Cell Lysis by DNA Damage}

Because unrepaired damaged DNA is harmful not only for individual cells but also for the cell population, cell death/lysis may result when genomic DNA is severely damaged. To assess this in E. coli, changes of turbidity and colony-forming units (CFU) were examined in the lon mutant $5 \mathrm{~h}$ after the addition of MMC (Figure 1a). We assumed that SulA was a key factor to check DNA repair by preventing DNA replication until DNA damage had been cured. Compared to controls, the addition of MMC caused a sharp decrease in CFU with a 10,000-fold difference at $17 \mathrm{~h}$ (12 h after the addition of MMC) and a decrease in $\mathrm{OD}_{600}$ for 11 to $71 \mathrm{~h}\left(6 \mathrm{~h}\right.$ to $66 \mathrm{~h}$ after the addition of MMC). Since the reduction in $\mathrm{OD}_{600}$ and flouting materials like those seen in phage lambda-directed lysis were like those of the $\sigma E-d e p e n d e n t$ cell lysis, which was seen in the early stationary phase and was enhanced by overexpression of the $\sigma E$ gene $[19,20]$; protein accumulation in the medium fraction after removal of the cell fraction by a low-speed centrifugation was analyzed by SDS-PAGE (Figure 1c). Strong protein bands were seen in samples from $17 \mathrm{~h}$ to $71 \mathrm{~h}(12 \mathrm{~h}$ to $66 \mathrm{~h}$ after the addition of MMC), but hardly seen in the control without MMC. In addition, when the same experiments with MMC were performed without supplementation of kanamycin, similar intensity patterns of protein bands were observed, indicating that observed effects were not influenced by the cells being stressed by the antibiotic being present in the medium. These data suggest that cell lysis occurs when DNA is damaged.

\subsection{Cell Lysis Triggered by Overexpression of sulA}

Effects of sulA overexpression on cell growth and cell lysis were examined. To avoid degradation of SulA by Lon protease, experiments were done with a lon mutant harboring pBAD-sulA, in which sulA was expressed from the araBAD promoter. The sulA overexpression induced by L-arabinose led to a reduction in $\mathrm{OD}_{600}$ and a 100 -fold decrease in $\mathrm{CFU}$ at $14 \mathrm{~h}$, corresponding to $9 \mathrm{~h}$ after arabinose addition (Figure $1 \mathrm{~b}$ ) and protein accumulation in the medium fraction (Figure 1d). Reductions in $\mathrm{OD}_{600}$ and CFU were like those by MMC, but the latter gave stronger effects. To confirm cell lysis, $\beta$-galactosidase activity was measured in the medium fraction as a cytoplasmic enzyme (Figure S1). Higher $\beta$-galactosidase activities were seen with sulA overexpression. Together these results imply that SulA accumulation causes cell lysis. 
(a)

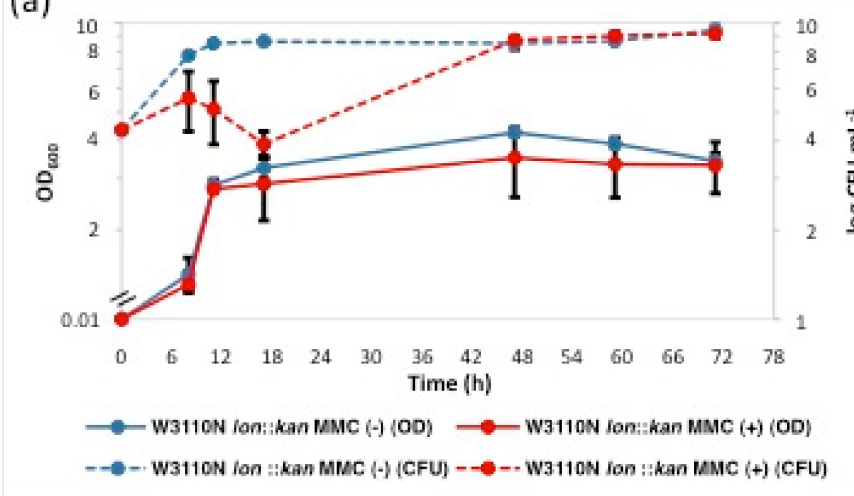

(b)

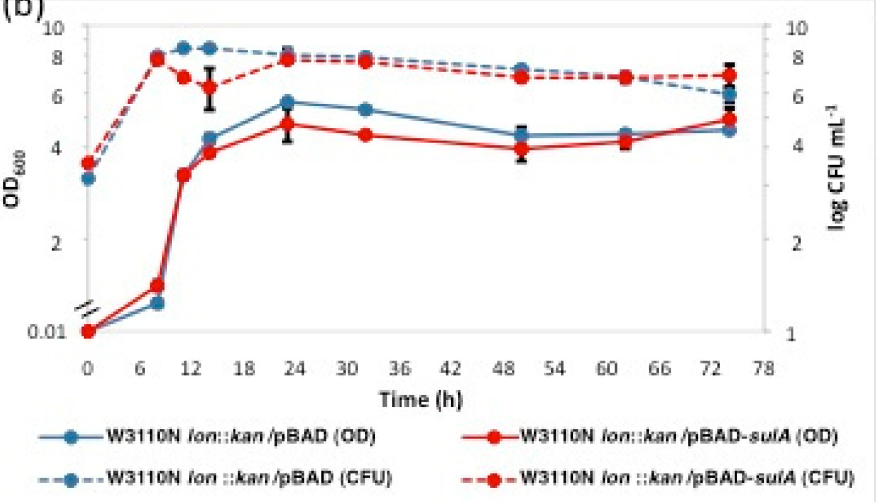

(c)

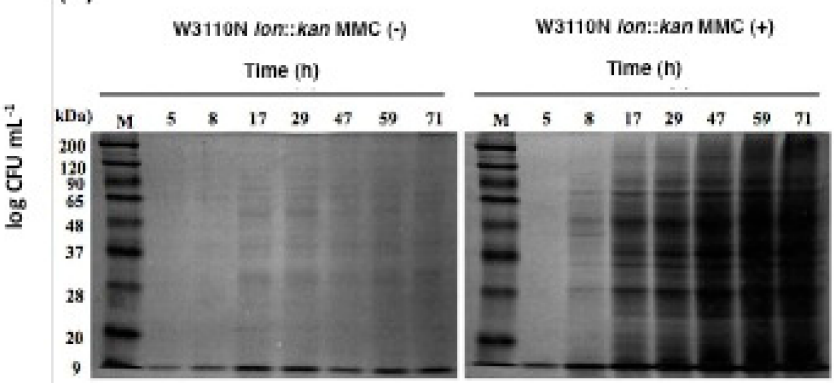

(d)
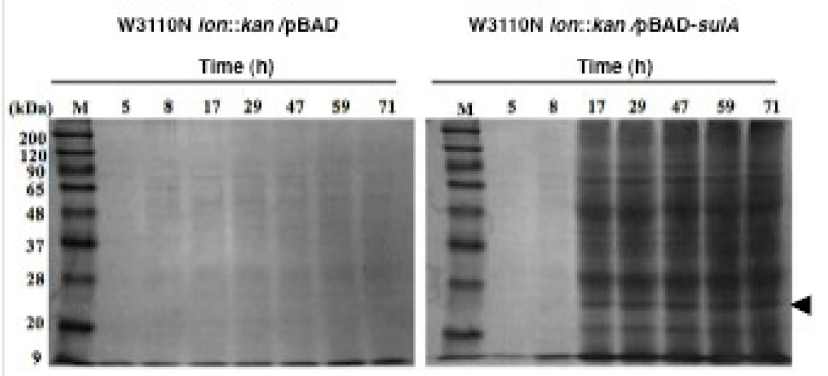

Figure 1. Effects of mitomycin $C$ and overexpression of sulA on cell growth and cell lysis. W3110N lon:kan cells were grown in LB medium containing kanamycin (a) and W3110N lon::kan cells harboring pBAD24 or pBAD-sulA (b) were grown in LB medium containing ampicillin and kanamycin, and mitomycin $\mathrm{C}(\mathrm{MMC})$ and L-arabinose were added at $5 \mathrm{~h}\left(\mathrm{OD}_{600}\right.$ of about 0.5 ) at the final concentrations of $0.1 \mu \mathrm{g} / \mathrm{mL}$ and $0.1 \%$, respectively. Cell turbidity (straight lines) and colony forming units (CFU) (dotted lines) were determined. Red circles and blue circles in (a) represent conditions with and without MMC, respectively; red circles and blue circles in (b) represent W3110N lon::kan cells harboring pBAD-sulA and W3110N lon::kan cells harboring pBAD24, respectively. Proteins from the medium fractions of cultures of W3110N lon::kan cells with and without MMC (c) and of W3110N lon::kan cells harboring pBAD-sulA and W3110N lon::kan cells harboring pBAD24 (d) were recovered and subjected to SDS-PAGE as described in the Materials and Methods Section. An arrowhead indicates the position of the size of SulA (18.8 kDa). Lane M is molecular markers. Error bars stand for \pm SD.

\subsection{Morphological Observation and Live/Dead Staining of Cells Grown under the Condition with} MMC or of Overexpression of sulA

Morphological changes by MMC and sulA overexpression occurred due to the SulA inhibition of cell division (Figure 2). Filamentous cells were seen at $2 \mathrm{~h}$ and $24 \mathrm{~h}$ after arabinose addition for sulA overexpression and at $2 \mathrm{~h}$ after MMC treatment, after which the numbers decreased drastically and rod-shaped cells were dominant at $24 \mathrm{~h}$. RT-PCR analysis showed sulA expression level by MMC was about 32-fold lower than by arabinose at $3 \mathrm{~h}$ (Figure S2). Therefore, the lower expression of sulA but similar or greater protein accumulation by MMC (Figure 1) suggests that there exists both SulA-dependent (SDCL) and SulA-independent (SICL) cell lysis pathways induced by DNA damage. Notably, W3110N $\Delta$ lon sulA::kan cells treated by MMC showed protein accumulation at a level like that of the wild type treated with MMC (Figure S3), but CFU did not recover to the control levels even after $48 \mathrm{~h}$ unlike W3110N lon::kan (Figure 1). The former results allow us to speculate that the SICL pathway is enhanced in the $\triangle$ sulA background and the latter suggests that sulA is required for recovery after MMC treatment. 


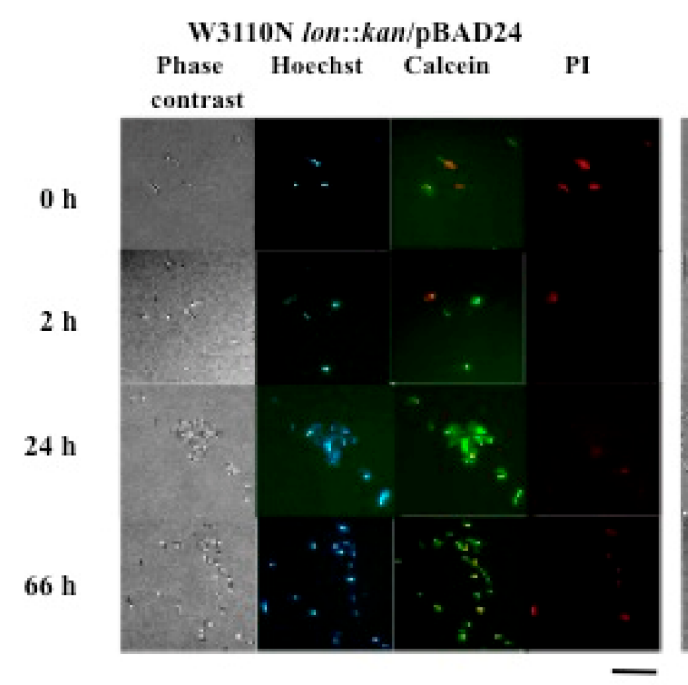

W3110N lon:kan MMC (-)

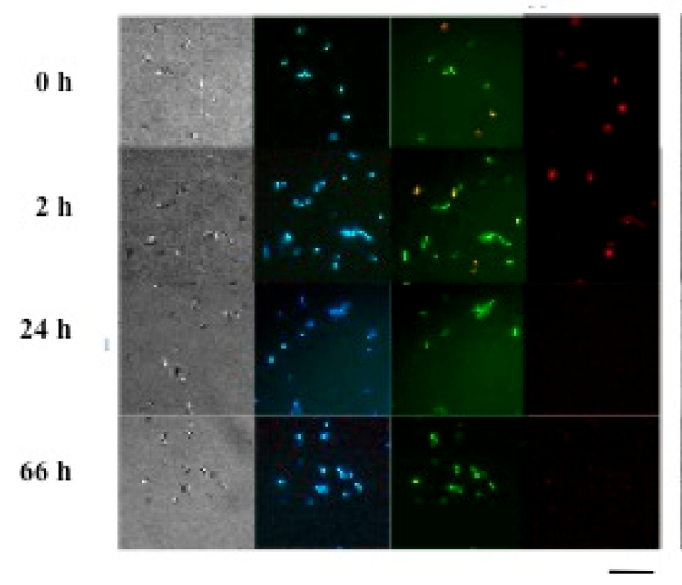

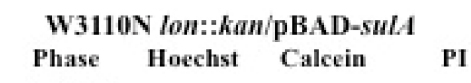
contrast

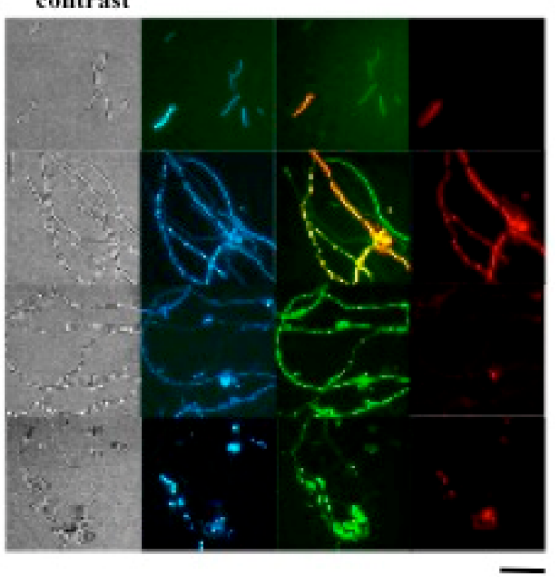

W3110N Lon::kan MMC (+)

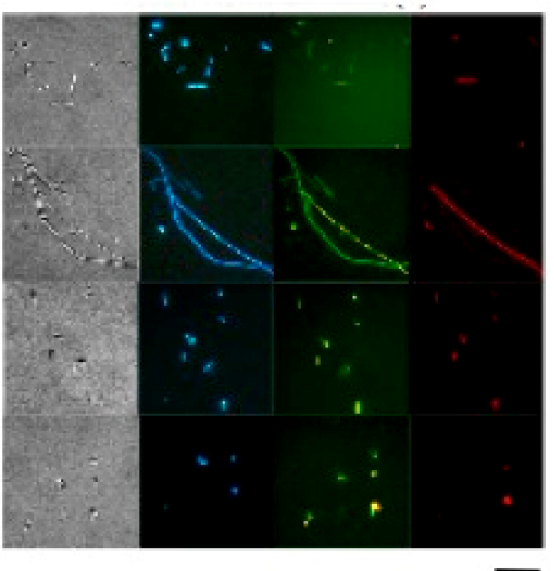

Figure 2. Morphological observation and live/dead staining of cells grown under the condition with MMC or with overexpression of sulA. W3110N lon::kan cells were grown in LB medium containing kanamycin; W3110N lon::kan cells harboring pBAD24 or pBAD-sulA were grown in LB medium containing ampicillin and kanamycin; $\mathrm{MMC}$ and L-arabinose were added at $\mathrm{OD}_{600}$ of about 0.5 at the final concentrations of $0.1 \mu \mathrm{g} / \mathrm{mL}$ and $0.1 \%$, respectively. Microscopic observation of cells was performed directly at or after staining with Hoechst; Calcein-AM, or PI Bars are $10 \mu \mathrm{m}$.

\subsection{Exploration of SulA Downstream Genes in the SDCL Pathway}

To uncover SulA downstream genes in the SDCL pathway, total RNA was isolated at $3 \mathrm{~h}$ after induction of sulA expression by arabinose and subjected to DNA microarray analysis. The sulA expression level was about 150-fold higher than in the no-arabinose control (Table S3). A total of 62 genes were up-regulated $>2$-fold and 51 were down-regulated, i.e., $<0.5$-fold (Tables S3 and S4). Up-regulated genes included 11 in energy metabolism and 18 for translation; down-regulated genes included 8 for central intermediary metabolism and 4 for energy metabolism. Fewer genes belonged to other cellular processes (Table S5).

Among candidates for SulA downstream genes (Tables S3 and S4), four that were significantly upregulated were chosen for further analysis $(\operatorname{sox} S, \operatorname{sod} A$, helD and $\operatorname{cs} p B)$. Of these, soxS, sod $A$ and helD are related to responses for oxidative stress or DNA damage. Additionally, $\operatorname{cs} B$ was selected because it was the most highly up-regulated gene among five belonging to the cold shock response family: $\operatorname{csp} B, \operatorname{csp} F, \operatorname{csp} G, \operatorname{csp} H$ and $\operatorname{cspI}$ (Table S3), and like $\operatorname{csp} A[21]$ may respond to other stresses. 


\subsection{Effects of Deletion and Overexpression of soxS, sodA, helD and $\operatorname{csp} B$}

To examine whether soxS, sodA, helD and $\operatorname{csp} B$ lie downstream from SulA in the SDCL pathway, BW25113 mutants deleted of these genes (Table S1) carrying pBAD-sulA were examined. As BW25113 can take up but not catabolize L-arabinose due to the $\triangle a r a B A D$ mutation (Table S1), induction of sulA expression by L-arabinose was expected to continue for longer periods. As a result, the $\triangle h e l D, \triangle \operatorname{csp} B$ and $\triangle \operatorname{sox} S$ mutants, but not the $\triangle$ sodA mutant, showed significantly lower protein accumulation compared to BW25113 (Figure 3a). However, $\triangle$ helD, $\triangle \operatorname{csp} B$ and $\triangle \operatorname{soxS}$ mutants showed higher turbidities than those of the wild type and $\triangle \operatorname{sod} A$, thus their low levels of protein accumulation were not due to their growth defects. Further experiments with BW25113 harboring pBADhelD, $\mathrm{pBAD}-\mathrm{csp} B$ or $\mathrm{pBAD}$-soxS (Figure $3 \mathrm{~b}$ ) revealed protein accumulation in the medium fraction for cultures in which helD or sox $S$ was overexpressed. These results suggest that HelD and SoxS lie downstream from SulA in the SDCL pathway and contribute the most. Considering these findings, no further experiments on other significantly up-regulated and down-regulated genes were performed.


Figure 3. Effects of disruption or overexpression of selected up-regulated genes by overexpression by sulA on SDCL. BW25113 helD::kan, BW25113 cspB::kan, BW25113 soxS::kan, and BW25113 sodA::kan cells harboring pBAD-sulA (a), and BW25113 cells harboring pCA24N-soxS, pCA24N-helD, or pCA24N-cspB (b), were grown in LB medium with ampicillin. L-Arabinose or IPTG was added at $\mathrm{OD}_{600}$ of about 0.5 at the final concentrations of $0.1 \%$ and $0.1 \mathrm{mM}$, respectively. Cultures were sampled by removing portions at $24 \mathrm{~h}$ after induction. Sample preparation for SDS-PAGE was performed as described in the Materials and Methods Section.

\subsection{Induction of soxS by sulA Overexpression}

An earlier report showed that soxS induction occurs in response to an increase in reactive oxygen species (ROS) [22], in which SoxR up-regulates soxS in response to redoxactive compounds under oxidative stress conditions [23]. Therefore, the intercellular ROS level was checked with the fluorescence probe $\mathrm{H}_{2}$ DCFDA after sulA overexpression. Results showed that upon induction with L-arabinose, ROS levels were similar in BW25113 cells harboring pBAD-sulA and in BW25113 control cells harboring an empty vector at $0 \mathrm{~h}$, $1 \mathrm{~h}, 3 \mathrm{~h}, 6 \mathrm{~h}$ and $12 \mathrm{~h}$ after induction. Yet, the $\Delta$ sox $\mathrm{R}$ mutant harboring pBAD-sulA showed similar protein band intensities in the medium fraction as the parental control harboring pBAD-sulA (Figure S4), suggesting that SoxR is not involved in the SDCL pathway. This 
finding is not unexpected because the SoxS regulon consists of genes under SoxS control and ones under the control of both SoxS and SoxR [24].

\subsection{Exploration of SoxS Downstream Genes in the SDCL Pathway}

As a DNA-binding dual transcription regulator, SoxS activates expression of 19 genes involved in defense against oxidative stress [24]. Thus, 16 non-essential SoxS downstream genes were examined with the corresponding deletion mutants harboring pBAD-sulA. Samples were taken from cultures at $24 \mathrm{~h}$ after L-arabinose induction where all strains except for $\triangle$ helD and $\Delta$ soxS mutants harboring pBAD-sulA showed almost similar levels of turbidity, and medium fractions were subjected to SDS-PAGE analysis. Results showed these mutants had only slight reductions of protein band intensities when compared with the control and greater intensities when compared with $\triangle$ helD and $\Delta$ soxS mutants harboring pBAD-sulA, as added controls (Figure S5). These data show that none of the 16 non-essential SoxS downstream genes are related to SDCL. Other experiments were then conducted to check for the involvement of the three essential genes of the SoxS regulon (ribA, lpxC and fldA) in the SDCL pathway.

\subsection{Overexpression of Essential Gene Candidate of the SoxS Regulon}

BW25113 harboring pCA24N-fldA, pCA24N-ribA or pCA24N-lpxC were examined by cell lysis assay after inducing gene expression with isopropyl $\beta$-D-thiogalactopyranoside (IPTG). Turbidities of BW25113 harboring pCA24N-fldA or pCA24N-ribA at $24 \mathrm{~h}$ were higher than that of BW25113 harboring pCA24N-lpxC. Results showed that cells carrying pCA24N-lpxC showed stronger protein intensity bands than those carrying pCA24N-fld A or pCA24N-ribA (Figure 4a). However, a large amount of a $28 \mathrm{kDa}$ band was seen for pCA24N plasmids. To eliminate the possibility that the $28 \mathrm{kDa}$ protein is responsible for cell lysis, BW25113 harboring pBAD-lpxC was evaluated. Overexpression of $l p x C$ showed much stronger protein band intensities for the medium fraction than control cells. Moreover, medium protein band intensities were comparable for BW25113 harboring pBAD-sulA, pBAD-soxS, and pBAD-lpxC (Figure 4b). Greater protein band intensities for BW25113 carrying pBAD-lpxC may result from difference in expression of $l p x C$, due to the distance of LpxC from the trigger far downstream from SulA. Taken together, these results suggest that LpxC is a SoxS downstream factor in the SDCL pathway.

(a)

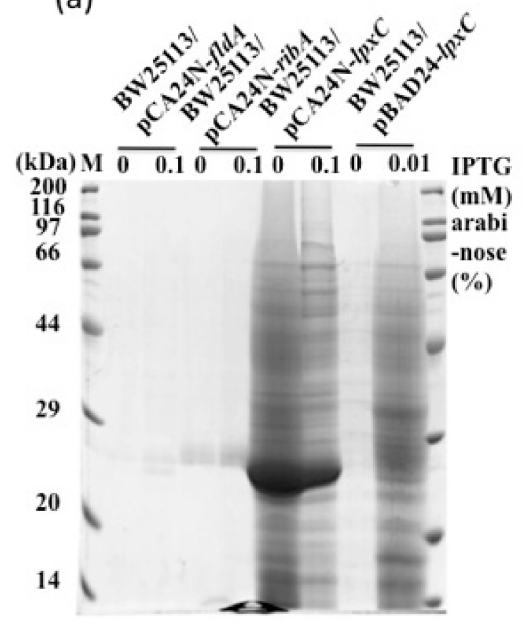

(b)

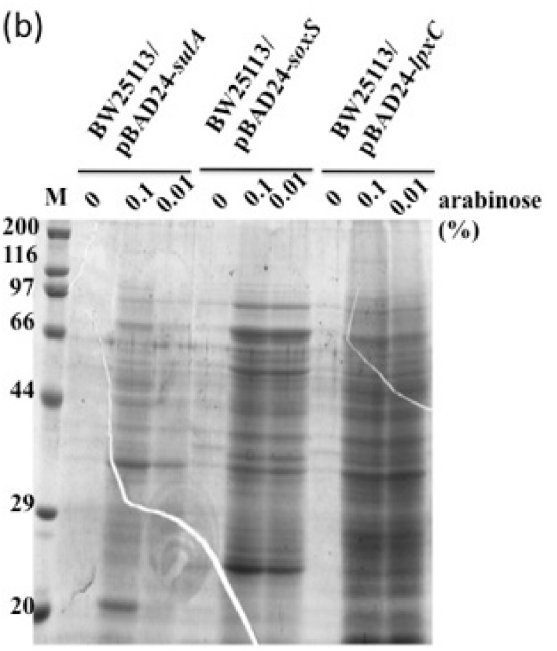

Figure 4. Effects of overexpression of selected SoxS regulon genes on SDCL. BW25113 cells harboring pCA24N-fldA, pCA24N-ribA, pCA24N-lpxC or pBAD-lpxC (a) and BW25113, BW25113 cells harboring pBAD-sulA, pBAD-soxS, or pBAD-lpxC (b) were grown in LB medium containing ampicillin. LArabinose and IPTG were added at $\mathrm{OD}_{600}$ of about 0.5 at the final concentrations of $0.1 \%$ or $0.01 \%$ and $0.1 \mathrm{mM}$, respectively. Portions of cultures were taken at $24 \mathrm{~h}$ after induction. Sample preparation for SDS-PAGE was performed as described in the Materials and Methods Section. 


\subsection{Effect of an Inhibitor for $L p x C$ on $S D C L$}

Since no $\triangle \operatorname{lp} x C$ mutant exists because $l p x C$ is an essential gene, effects of the LpxCspecific inhibitor CHIR-090 (MedChemExpress) were checked in cells overexpressing sulA or soxS (Figure 5). When cells harboring an empty vector were grown in the presence of $100 \mathrm{ng} / \mathrm{mL}$ or $1000 \mathrm{ng} / \mathrm{mL}$ of CHIR-090, strong medium fraction protein bands were seen, suggesting cell lysis by CHIR-090. Lysis may be due to severe inhibition of LpxC to a level below its requirement for cell proliferation. Further, CHIR-090 treatment of cells overexpressing sulA or soxS reduced protein band intensities in the medium fraction, implying that induction of LpxC synthesis by sulA or soxS overexpression was inhibited thereby reducing LpxC-directed cell lysis, but not cell proliferation due to some LpxC molecules escaping the inhibitor. These findings together with the results from overexpression of $l p x C$ suggest that LpxC lies downstream from SoxS and takes part in the SDCL pathway.

(a)



Figure 5. Effects of CHIR-090P, an LpxC inhibitor, on SDCL. BW25113 cells harboring pBAD24 (a), pBAD24-sulA (b) (SulA: $18.8 \mathrm{kDa}$ ) and pBAD24-soxS (c); (SoxS: $12.9 \mathrm{kDa}$ ) were grown in LB medium containing ampicillin. L-Arabinose (at a final concentration of 0.01\%) and CHIR-090 (at a final concentration of $0,1,10,100$ or $1000 \mathrm{ng} / \mathrm{mL}$ ) were added at $\mathrm{OD}_{600}$ of about 0.5 , and portions of the culture were taken at $24 \mathrm{~h}$ after induction. Sample preparation for SDS-PAGE was performed as described in the Materials and Methods Section.

\subsection{Relationship of the SDCL Pathway with Known Cell Death Pathways}

There are two known cell death pathways triggered by DNA damage in E. coli: mazEFmediated cell death pathway [25] and the apoptosis-like death (ALD) pathway [26]. The former blocks operation of the latter. The latter is characterized by membrane depolarization and DNA fragmentation, which are hallmarks of eukaryote mitochondrial apoptosis and up-regulation of a unique set of genes called extensive-damage-induced (Edin) genes [26].

Studies focused on mazEF and $r y b B$ as key genes, which are analogous to the Edin genes because $r y b B$ is a key gene in the $\sigma \mathrm{E}$-dependent cell lysis pathway, which is triggered by ROS in the early stationary phase [20,27]. Experiments with BW25113 $\operatorname{mazEF}$ harboring pBAD-sulA and BW25113 $\triangle r y b B$ harboring $\mathrm{pBAD}$-sulA were thus performed. Strong medium protein band intensities like those of BW25113 harboring pBAD-sulA as a control were from both strains (Figure S6a,b). These results and the finding that ALD is tightly associated with the formation of $\mathrm{OH}^{\cdot}$ [26] but almost no increase in ROS occurs in SDCL suggest that the SDCL pathway does not overlap with mazEF-mediated cell death pathway nor with the ALD pathway.

\section{Discussion}

Based on the idea that severely DNA-damaged cells are eliminated from cell populations, we focused on SulA as the trigger that acts as a checkpoint protein to block cell 
division by inhibition of FtsZ polymerization in response to DNA damage in E. coli $[12,14]$ and investigated the effects of sulA overexpression and SulA accumulation on cell morphology, cell death and lysis. Analysis of protein accumulation in the medium fraction revealed that overexpression of sulA resulted in cell lysis to the extent of that found by MMC treatment (Figure 1). The lower expression of sulA but similar or greater protein accumulation by MMC and protein accumulation in the $\triangle$ sulA background imply that there are also SICL pathways. Our findings suggest that SICL pathways include the ALD [26] and mazEF-cell death pathways [25] because both are induced by DNA damage and shown not to overlap with SDCL (Figure S6a,b).

Factor(s) downstream from SulA in the SDCL pathway were investigated by transcriptome analysis to find gene candidates downstream of SulA. Gene candidates were examined by using the respective deletion mutants and by overexpression, suggesting SoxS together with HelD are found downstream from SulA. However, no increase in ROS was found with sulA overexpression; nor was an involvement of SoxR in SDCL (Figure S4). Further experiments with 19 deletion and overexpression strains for genes in the SoxS regulon suggested that $\mathrm{LpxC}$ is a main player downstream from SoxS in SDCL. Cell lysis caused by helD (encoding helicase IV that interacts with ssDNA) overexpression is consistent with the earlier report that even a modest level of helD overexpression may be lethal [28]. Additionally, helD overexpression causes a filamentous cell morphology [29] and may enhance the filamentous phenotype by SulA. There is no further evidence on the factors downstream from HelD in HelD-dependent cell lysis.

Earlier reports gave a line of evidence to explain the cell lysis by overproduction of LpxC. Sutterlina et al. [30], reported a novel cell death pathway triggered by a dominant mlaA mutation that removes phospholipids from the outer leaflet of the outer membrane $(\mathrm{OM})$, in which LpxC may be involved. LpxC catalyzes the first committed step in LPS biosynthesis and the level of LPS is tightly regulated by FtsH/LapB/LapC complex and HslUV protease [31,32] and excessive production of LPS is toxic to cells $[33,34]$. The ftsH1 (Ts) mutation increases the amount of lipopolysaccharide at the non-permissive temperature due to a dramatic increase for LpxC, UDP-3-O-(R-hydroxymyristoyl)-Nacetylglucosamine deacetylase [33]. It has been proposed that the mlaA allele-directed cell death is initiated by destabilization of the OM to produce OM vesicles and subsequently, the lipids lost from the OM are replaced by the lipids from the inner membrane (IM), resulting in a shrink of the IM, reduction of the cytoplasmic volume and increase in its density, which finally, leads to the mechanical rupture of the IM and cell lysis [30]. As in this proposal, the increased level of LPS by overproduction of LpxC may lead to destabilization of the OM and initiation of cell lysis.

Based on our findings, we propose the SDCL pathway model for cell death and lysis by DNA damage that is shown schematically in Figure 6. Our study suggests that the SDCL pathway does not overlap with the mazEF-mediated [25] or ALD pathway [26], which are also induced by DNA damage. In the SDCL pathway, SoxS activates $1 p x C$ expression without any factor(s) linking SulA and SoxS. Measurements of ROS revealed that overexpression of sulA caused a slight change in ROS levels, while $\operatorname{sod} A$ was induced under the same conditions. These inconsistent findings are understandable if a trace amount of ROS can induce sodA or the negative regulation of sodA by Fur or ArcA [35] is released. In addition, it is known that the induction of sox $S$ occurs not only by oxidative stress but also via cross-regulation by other transcription regulator(s) [36]. DNA damage induces sulA expression as an SOS response. If SulA exists stably due to DNA damage being too severe to be completely repaired, the SDCL pathway, composed of SulA, SoxS, and LpxC, is evoked to promote cell lysis. Further research, however, is required to show a direct link between SulA, SoxS and LpxC. On the other hand, HelD is responsible for alternative cell lysis in the SDCL pathway, which is different from the SoxS-directed cell lysis. 


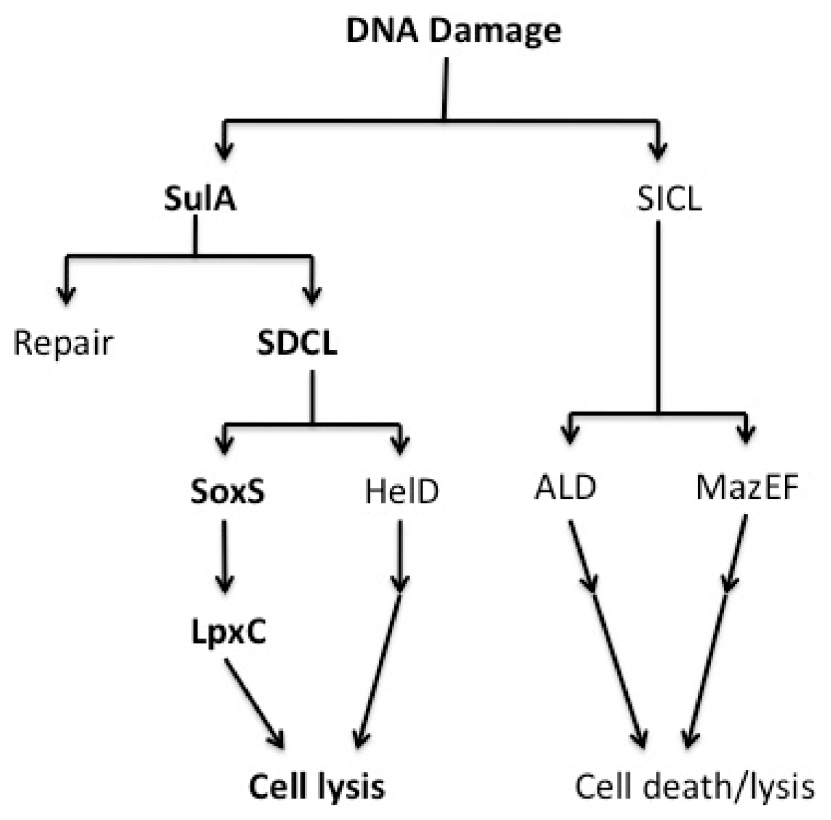

Figure 6. Pathways of SDCL following severe DNA damage. Details are described in the text.

\section{Materials and Methods}

\subsection{Bacterial Strains, Medium and Culture Conditions}

Bacterial strains used in this study were derivatives of E. coli K-12. Their relevant genotypes and plasmids are shown in Table S1. For experiments with gene-disrupted mutants, BW25113 derivatives [37] or W3110N [38] derivatives were used. The transfer of lon::kan or sulA::kan from BW25113 lon::kan or BW25113 sulA::kan to W3110N, and the transfer of sulA::kan from BW25113 sulA::kan to W3110N $\Delta$ lon were performed by P1 transduction according to the procedure previously described [39]. The construction of mazEF::kan in BW25113 and the removal of kan from W3110N lon::kan and W3110N sulA::kan were performed with pCP20 according to the procedure previously described [40]. The first generated allele of mazEF::kan was further transferred into BW25113 by P1 transduction, generating BW25113 mazEF::kan. The construction was confirmed by PCR with the genomic DNA of the transductant as a template. For gene overexpression, pCA24N recombinants of specific genes under control of an IPTG-inducible promoter in an ASKA library [41] or pBAD24 [42] recombinants of specific genes under control of an L-arabinose-inducible promoter were used. Liquid culture was performed by using modified Luria-Bertani (LB) medium (1\% Bacto Tryptone (Nacalai Tesque, Japan), 0.5\% yeast extract (Nacalai Tesque, Japan), $0.5 \% \mathrm{NaCl}$ ) at $37^{\circ} \mathrm{C}$ under aerobic conditions by reciprocal shaking (100 times $\left./ \mathrm{min}\right)$. In growth experiments, precultured cells were inoculated into LB ( $0.1 \%$ of total volume), and cell growth was seen by monitoring turbidity or CFU. Appropriate antibiotics were added at the following final concentrations: ampicillin (Meiji Seika, Japan), $50 \mu \mathrm{g} / \mathrm{mL}$; chloramphenicol (Wako, Japan), $20 \mu \mathrm{g} / \mathrm{mL}$; and kanamycin (Meiji Seika Kaisha, Japan.), $25 \mu \mathrm{g} / \mathrm{mL}$. MMC (Wako, Japan) was added as a mutagen at a final concentration of $0.1 \mu \mathrm{g} / \mathrm{mL}$. L-arabinose and IPTG were added at final concentrations of $0.1 \%$ and 0.1 or $0.01 \mathrm{mM}$, respectively, into the culture at around $\mathrm{OD}_{600}$ of 0.5 to induce the expression of genes that had been cloned.

\subsection{DNA Manipulation}

Conventional recombinant DNA techniques [43] were applied for DNA manipulation. For construction of $\mathrm{pBAD}$ recombinants, DNA fragments bearing the coding regions of sulA, soxS, lpxC and helD were amplified by polymerase chain reaction (PCR) using primers with an EcoRI or HindIII recognition sequence and genomic DNA as a template. The primers used are shown in Table S2. The amplified PCR products were purified by using a QIAquick PCR Purification kit (Qiagen, The Netherlands). The DNA fragments of 
pBAD24 after digestion with EcoRI and HindIII were also purified by using the same kit and were treated with Shrimp alkaline phosphatase (TAKARA, Japan) followed by heating to inactivate the enzyme. The fragments were further purified by using the same kit. Both fragments were ligated by using Ligation high Ver.2 (Toyobo, Japan). The ligated materials were introduced into Competent high DH5 $\alpha$ (Toyobo, Japan). Similarly, for construction of pCAN24 recombinants, DNA fragments bearing the coding regions of sulA and soxS were amplified by PCR using one primer with a NotI recognition sequence and another primer without a restriction enzyme recognition sequence and genomic DNA as a template. The fragments were digested with NotI and ligated with NotI and StuI double digested pCA24N fragments. Plasmid DNAs in transformants were purified by using a QIAprep Spin Miniprep kit (Qiagen, The Netherlands). The construction of plasmid recombinants was confirmed by restriction mapping.

\subsection{Analysis of Proteins in the Medium Fraction}

During cultivation, $1.0 \mathrm{~mL}$ of the culture medium was taken and subjected to centrifugation at $3000 \mathrm{rpm}$ for $10 \mathrm{~min}$ to separate the supernatant (medium fraction) and the precipitate. Proteins in the medium fraction were recovered by centrifugation at $3000 \mathrm{rpm}$ for $10 \mathrm{~min}$ after the addition of trichloroacetic acid at a final concentration of $10 \%$ and kept on ice for $30 \mathrm{~min}$. The precipitate was washed with diethyl ether and resuspended with $100 \mu \mathrm{L}$ of $20 \mathrm{mM}$ Tris- $\mathrm{HCl}$ (pH 7.0). After addition of sodium dodecyl sulfate (SDS) at a final concentration of $1 \%$ and 2-mercaptoethanol at a final concentration of $0.5 \%, 30 \mu \mathrm{L}$ of the medium fraction was heated at $70^{\circ} \mathrm{C}$ for $10 \mathrm{~min}$ with a small amount of sucrose and then applied onto SDS-12\% PAGE. The proteins separated on the gel were stained with Coomassie brilliant blue R250.

\subsection{Reverse Transcriptase-Polymerase Chain Reaction (RT-PCR)}

Total RNA was prepared from W3110N lon::kan cells grown without or with MMC or from W3110N lon::kan cells harboring pBAD-sulA, which were grown in LB medium for $1 \mathrm{~h}$ and $3 \mathrm{~h}$ after induction at $37^{\circ} \mathrm{C}$, by the hot phenol method [44]. The concentration of RNA was estimated spectrophotometrically at $260 \mathrm{~nm}$. RT-PCR analysis was performed by using the mRNA Selective RT-PCR Kit (TAKARA, Japan) with $0.1 \mu \mathrm{g}$ of RNA as a template and primer sets (Table S2) to examine the expression of targeted genes as performed previously [45]. RT reaction was conducted at $45^{\circ} \mathrm{C}$ for $15 \mathrm{~min}$ with $0.1 \mu \mathrm{g}$ of total RNA and each downstream primer, and then, PCR reaction was conducted at $85^{\circ} \mathrm{C}$ for $1 \mathrm{~min}$ for denaturing, at $45^{\circ} \mathrm{C}$ for $1 \mathrm{~min}$ for annealing and at $72{ }^{\circ} \mathrm{C}$ for $1 \mathrm{~min}$ for extension by using the two primers for each gene. The PCR products after 15, 20, 25 and 30 cycles were analyzed by $0.9 \%$ agarose gel electrophoresis and stained with ethidium bromide. As a control, $10 \mu \mathrm{g}$ of total RNA was run by $1.2 \%$ agarose gel electrophoresis, followed by staining with ethidium bromide. The intensity of bands of RT-PCR products was quantitatively determined using ImageJ. Linearity of the amplification was seen up to the 25th or 30th cycle. Under our experimental conditions, RT-PCR was able to specifically detect mRNA because no band was seen when reverse transcriptase was omitted.

\subsection{Cell Staining and Morphological Observation}

Cells were collected from $1 \mathrm{~mL}$ of the culture medium by centrifugation and washed with $50 \mathrm{mM}$ potassium phosphate buffer ( $\mathrm{pH}$ 6.5). After resuspension with the same buffer, staining of the cells was performed with Hoechist 33258 for observation of all cells, with Calcein-AM for the observation of viable cells and with propidium iodide (PI) (Wako, Japan) for observation of membrane-permeabilized cells (dead cells) for $15 \mathrm{~min}$ in the dark at concentrations of $5 \mu \mathrm{g} / \mathrm{mL}$ for Hoechist, $10 \mu \mathrm{g} / \mathrm{mL}$ for Calcein and $0.5 \mu \mathrm{g} / \mathrm{mL}$ for PI according to the supplier's instructions. Samples were observed using a Nikon E600 microscope with fluorescence capability (Nikon, Japan). 


\subsection{Measurement of $\beta$-Galactosidase Activity}

$\beta$-Galactosidase activity was measured according to the method of Miller [39]. During cultivation, $1.0 \mathrm{~mL}$ of the culture medium was taken and subjected to centrifugation at $3000 \mathrm{rpm}$ for $10 \mathrm{~min}$ to separate the medium and cell fractions. Cells in the cell fraction were resuspended in LB medium and treated with toluene. The medium fraction and cell fraction were each mixed with $\mathrm{Z}$ buffer $\left(16.1 \mathrm{~g} / \mathrm{L} \mathrm{Na}_{2} \mathrm{HPO}_{4} \cdot 7 \mathrm{H}_{2} \mathrm{O}, 5.5 \mathrm{~g} / \mathrm{L} \mathrm{NaH}_{2} \mathrm{PO}_{4} \cdot \mathrm{H}_{2} \mathrm{O}, 0.75 \mathrm{~g} / \mathrm{L}\right.$ $\mathrm{KCl}$ and $0.24 \mathrm{~g} / \mathrm{L} \mathrm{MgSO}_{4} \cdot 7 \mathrm{H}_{2} \mathrm{O}(\mathrm{pH} 7.0)$ ). Enzyme reaction was started by the addition of $o$-nitrophenyl- $\beta$-D-galactopyranoside (Wako, Japan) and stopped by the addition of $1 \mathrm{M}$ $\mathrm{Na}_{2} \mathrm{CO}_{3}$. The intensities of color and turbidity were measured spectrophotometrically at $\mathrm{OD}_{420}$ and $\mathrm{OD}_{550} \mathrm{~nm}$, respectively, and the activity of each sample was calculated as a Miller unit by using the established formula.

\subsection{RNA Isolation and Preparation of DNA Microarrays}

Total RNA was prepared from W3110N lon::kan cells harboring pBAD24 or pBAD-sulA, which were grown in LB medium containing ampicillin $3 \mathrm{~h}$ after induction by L-arabinose, by the hot phenol method [44]. After phenol/chloroform treatment and ethanol precipitation, the resultant RNA (about $100 \mu \mathrm{g}$ ) was resuspended in $100 \mathrm{mM}$ sodium acetate, $\mathrm{pH} 5.5,50 \mathrm{mM} \mathrm{MgSO}_{4}$ and treated at $37^{\circ} \mathrm{C}$ for $1 \mathrm{~h}$ with 10 units of RNase-free DNAase (TAKARA, Japan) in a final volume of $100 \mu \mathrm{L}$. RNA was recovered after phenol/chloroform treatment and ethanol precipitation. The RNA concentration was estimated spectrophotometrically at $260 \mathrm{~nm}$. DNA microarrays were prepared using synthetic 65-bp oligos designed for E. coliI-K12, O157 sakai and EDL genes (Sigma Genosys, Japan). The oligos were diluted with Pront universal microarray reagent (Corning, Glendale, AZ, USA) at $80 \mu \mathrm{M}$ and spotted on ULTRA GAPS type 7 slides (Amersham Pharmacia Biotech, Inc., Erie, PA, USA) by using a Lucidea array spotter (Amersham Pharmacia Biotech, Inc., Erie, PA, USA). The spotted array DNAs were immediately UV-crosslinked with the array slides in UV stratalinker 1800 (Stratagene, La Jolla, CA, USA). Fluorescent-labeled cDNA preparation was performed with a Cyscribe post-labelling kit (Amersham BioSciences, UK) and a Cyscribe GFX purification kit (Amersham BioSciences, UK). Labelling of amino allylmodified cDNA was performed with CyDYE (Amersham BioSciences, UK). The labeled cDNAs were purified with a Cyscribe GFX purification kit (Amersham BioSciences, UK). Before the hybridization of labeled probes with array DNAs, the DNA microarray slides were incubated in a prehybridization buffer $(5 \times \mathrm{SSC}, 0.1 \% \mathrm{SDS}, 1 \% \mathrm{BSA})$ at $42{ }^{\circ} \mathrm{C}$ for $45 \mathrm{~min}$ (prehybridization). The labeled probes were mixed with a probe solution (final concentration of 50\% formamide, $6 \times$ SSC, $0.6 \%$ SDS, $5 \times$ Denhardt's solution) and hybridized with array DNAs on DNA microarrays at $42{ }^{\circ} \mathrm{C}$ overnight. The slides were washed with Wash I $(2 \times$ SSC, $0.1 \%$ SDS $)$, Wash II $(0.2 \times$ SSC $)$ and Wash III solution at $42{ }^{\circ} \mathrm{C}$ for $2 \mathrm{~min}$ in each washing step. After the washing steps, the slides were dried and scanned with an FLA-8000 array scanner (Fiji Film, Japan) at 532 (Сy3) and 635 (Сy5) nm. Because our DNA microarray has spots including non-K-12 oligos (designed for pathogenic E. coli) and blank spots in a total of 12,288 spots, we selected 10 spots including the oligos for O157 genes ECs4964, ECs4965, ECs4966, ECs2142 and ECs2143 as negative control spots. To check the hybridization efficiency, the oligos for $16 \mathrm{~S}$ rRNA were also spotted as positive control spots. The Cy3 and Cy5 fluorescent intensity values of each oligo were subtracted with the fluorescent intensity value calculated from negative control oligos (average + 1SD) in 10 negative control spots. The relative ratio of $\mathrm{Cy} 5$ and $\mathrm{Cy} 3$ was calculated and global normalization was performed for the average value of the $\log \mathrm{Cy} 5 / \mathrm{Cy} 3$ ratio of all oligos against $E$. coli $\mathrm{K}-12$ genes to be 0 . More than one oligos were designed for each gene and at least two independent spots were spotted for one oligo. Then, we selected the up or down oligos based on relative ratio of $\mathrm{Cy} 5$ and $\mathrm{Cy} 3$ : lower $(<0.5$, i.e., a negative fold difference) or higher (>2.0, i.e., a positive fold difference) ratios of the sulA overexpression sample (Cy5) to the control sample (Cy3) were significant differences. Then we selected the genes corresponding to the up or down oligos as the up and down genes in the sulA overexpression sample. Functional classification of genes was performed according to the 
EcoCyc [46] and KEGG [47] databases. The functions of genes were derived or inferred from the GenoBase, SWISS-PROT and NCBI databases.

\subsection{Measurement of Intracellular ROS}

The amounts of ROS inside cells were measured with an oxidant-sensitive probe, $2^{\prime}, 7^{\prime}$ dichlorofluorescin diacetate, $\mathrm{H}_{2}$ DCFDA (Sigma-Aldrich, St. Louis, MO, USA) [27]. This probe is trapped inside the cells after cleavage of the diacetate by an intracellular esterase. It is then oxidized by radical species (mostly $\mathrm{H}_{2} \mathrm{O}_{2}$ ) with a more fluorescent compound being produced. Cells were grown in LB medium containing $\mathrm{H}_{2}$ DCFDA at a final concentration of $4 \mu \mathrm{M}$. Aliquots were then washed once with saline, resuspended in the same solution, and subjected to sonic oscillation. The cell extracts were centrifuged at $4000 \mathrm{rpm}$ for $10 \mathrm{~min}$ and the supernatants were used. The fluorescence from the supernatants was measured with $\lambda_{\mathrm{EX}}=502 \mathrm{~nm}$ and $\lambda_{\mathrm{EM}}=524 \mathrm{~nm}$ using a fluorescence spectrophotometer (Hitachi, Japan). Protein concentration was determined by the Lowry method [48]. The value of $\lambda_{\mathrm{EM}}=524 \mathrm{~nm}$ was normalized to the protein concentration in each sample.

\subsection{Statistical Analyses}

All experiments were performed independently at least three times, except for fluorescence microscopy and transcriptome analysis. The values of OD, CFU and $\beta$-galactosidase activity are shown with standard deviations. For morphology observation by a fluorescence microscope, we chose a typical image from at least ten random images. Transcriptome analysis and its statistical analysis were described above.

Supplementary Materials: The following are available online at https:/ / www.mdpi.com/article / 10.3390/ijms22094535/s1, Figure S1: $\beta$-Galactosidase activity in the medium fraction, Figure S2: Expression level of sulA under the condition with MMC or with overexpression of sulA, Figure S3: Effects of mitomycin $C$ on cell growth and cell lysis, Figure S4: Effect of disrupted mutation of soxR on SDCL, Figure S5: Effects of disrupted mutation of 16 SoxS regulon genes on SDCL, Figure S6: Effects of $\triangle r y b B$ and $\triangle m a z E F$ on SDCL, Table S1: Bacterial strains and plasmids, Table S2: Primers used in this study. Table S3: Significantly up-regulated genes by overexpression of sulA, Table S4: Significantly down-regulated genes by overexpression of sulA, Table S5: Summary of significantly up-regulated and down-regulated genes by overexpression of sulA.

Author Contributions: M.Y. and M.M. conceived and designed the experiments; K.N., N.O., A.O., R.M., K.F., and M.M. performed the experiments; T.O. and H.M. performed DNA microarray; M.M., T.K., and M.Y. supervised the experiments; B.L.W. and H.M. supervised the construction of strains and plasmids; M.Y. authored the paper; and B.L.W. improved and corrected the style of the article. All authors have read and agreed to the published version of the manuscript.

Funding: This research was funded by the Japan Society for the Promotion of Science, MEXT/JSPS Kakenhi (25250028 and 16H02485 to H.M. and M.Y.).

Institutional Review Board Statement: Not applicable.

Informed Consent Statement: Not applicable.

Data Availability Statement: Array data are accessible through ArrayExpress accession number A-MTAB-684.

Acknowledgments: We thank K. Matsushita, T. Yakushi and N. Kataoka for helpful discussions.

Conflicts of Interest: The authors declare no conflict of interest.

\section{References}

1. Shieh, S.-Y.; Ikeda, M.; Taya, Y.; Prives, C. DNA Damage-Induced Phosphorylation of p53 Alleviates Inhibition by MDM2. Cell 1997, 91, 325-334. [CrossRef]

2. $\quad$ Banin, S.; Moyal, L.; Shieh, S.-Y.; Taya, Y.; Anderson, C.W.; Chessa, L.; Smorodinsky, N.I.; Prives, C.; Reiss, Y.; Shiloh, Y.; et al. Enhanced Phosphorylation of p53 by ATM in Response to DNA Damage. Science 1998, 281, 1674-1677. [CrossRef] [PubMed]

3. Shieh, S.-Y.; Taya, Y.; Prives, C. DNA damage-inducible phosphorylation of p53 at N-terminal sites including a novel site, Ser20, requires tetramerization. EMBO J. 1999, 18, 1815-1823. [CrossRef] 
4. $\quad$ El-Deiry, W.S.; Tokino, T.; Velculescu, V.E.; Levy, D.B.; Parsons, R.; Trent, J.M.; Lin, D.; Mercer, W.E.; Kinzler, K.W.; Vogelstein, B. WAF1, a potential mediator of p53 tumor suppression. Cell 1993, 75, 817-825. [CrossRef]

5. Bertoli, C.; Skotheim, J.M.; De Bruin, R.A.M. Control of cell cycle transcription during G1 and S phases. Nat. Rev. Mol. Cell Biol. 2013, 14, 518-528. [CrossRef]

6. D'Orazi, G.; Cecchinelli, B.; Bruno, T.; Manni, I.; Higashimoto, Y.; Saito, S.; Gostissa, M.; Coen, S.; Marchetti, A.; Del Sal, G.; et al. Homeodomain-interacting protein kinase-2 phosphorylates p53 at Ser 46 and mediates apoptosis. Nat. Cell Biol. 2002, 4, 11-19. [CrossRef] [PubMed]

7. Oda, K.; Arakawa, H.; Tanaka, T.; Matsuda, K.; Tanikawa, C.; Mori, T.; Nishimori, H.; Tamai, K.; Tokino, T.; Nakamura, Y.; et al. p53AIP1, a Potential Mediator of p53-Dependent Apoptosis, and Its Regulation by Ser-46-Phosphorylated p53. Cell 2000, 102, 849-862. [CrossRef]

8. $\quad$ Friedberg, E.C.; Walker, G.C.; Siede, W.; Wood, R.D.; Schultz, R.A.; Ellenberger, T. DNA Repair and Mutagenesis, 2nd ed.; American Society for Microbiology: Washington, DC, USA, 2005.

9. De Henestrosa, A.R.F.; Ogi, T.; Aoyagi, S.; Chafin, D.; Hayes, J.J.; Ohmori, H.; Woodgate, R. Identification of additional genes belonging to the LexA regulon in Escherichia coli. Mol. Microbiol. 2002, 35, 1560-1572. [CrossRef]

10. Patel, M.; Jiang, Q.; Woodgate, R.; Cox, M.M.; Goodman, M.F. A new model for SOS-induced mutagenesis: How RecA protein activates DNA polymerase V. Crit. Rev. Biochem. Mol. Biol. 2010, 45, 171-184. [CrossRef]

11. Singletary, L.A.; Gibson, J.L.; Tanner, E.J.; McKenzie, G.J.; Lee, P.L.; Gonzalez, C.; Rosenberg, S.M. An SOS-Regulated Type 2 Toxin-Antitoxin System. J. Bacteriol. 2009, 191, 7456-7465. [CrossRef] [PubMed]

12. Dajkovic, A.; Mukherjee, A.; Lutkenhaus, J. Investigation of Regulation of FtsZ Assembly by SulA and Development of a Model for FtsZ Polymerization. J. Bacteriol. 2008, 190, 2513-2526. [CrossRef] [PubMed]

13. Napolitano, R.; Janel-Bintz, R.; Wagner, J.; Fuchs, R.P.P. All three SOS-inducible DNA polymerases (Pol II, Pol IV and Pol V) are involved in induced mutagenesis. EMBO J. 2000, 19, 6259-6265. [CrossRef] [PubMed]

14. Lewis, K. Programmed Death in Bacteria. Microbiol. Mol. Biol. Rev. 2000, 64, 503-514. [CrossRef]

15. Charette, M.F.; Henderson, G.W.; Markovitz, A. ATP hydrolysis-dependent protease activity of the lon (capR) protein of Escherichia coli K-12. Proc. Natl. Acad. Sci. USA 1981, 78, 4728-4732. [CrossRef] [PubMed]

16. Seong, I.S.; Oh, J.Y.; Yoo, S.J.; Seol, J.H.; Chung, C.H. ATP-dependent degradation of SulA, a cell division inhibitor, by the HslVU protease in Escherichia coli. FEBS Lett. 1999, 456, 211-214. [CrossRef]

17. Bizanek, R.; McGuinness, B.F.; Nakanishi, K.; Tomasz, M. Isolation and structure of an intrastrand cross-link adduct of mitomycin C and DNA. Biochemistry 1992, 31, 3084-3091. [CrossRef]

18. Keller, K.L.; Overbeck-Carrick, T.L.; Beck, D.J. Survival and induction of SOS in Escherichia coli treated with cisplatin, UVirradiation, or mitomycin C are dependent on the function of the RecBC and RecFOR pathways of homologous recombination. Mutat. Res. Repair 2001, 486, 21-29. [CrossRef]

19. Nitta, T.; Nagamitsu, H.; Murata, M.; Izu, H.; Yamada, M. Function of the $\sigma E$ Regulon in Dead-Cell Lysis in Stationary-Phase Escherichia coli. J. Bacteriol. 2000, 182, 5231-5237. [CrossRef]

20. Murata, M.; Noor, R.; Nagamitsu, H.; Tanaka, S.; Yamada, M. Novel pathway directed by $\sigma$ E to cause cell lysis in Escherichia coli. Genes Cells 2012, 17, 234-247. [CrossRef] [PubMed]

21. Brandi, A.; Giangrossi, M.; Giuliodori, A.M.; Falconi, M. An Interplay among FIS, H-NS, and Guanosine Tetraphosphate Modulates Transcription of the Escherichia coli cspA Gene under Physiological Growth Conditions. Front. Mol. Biosci. 2016, 3, 19. [CrossRef]

22. Imlay, J.A. Cellular Defenses against Superoxide and Hydrogen Peroxide. Annu. Rev. Biochem. 2008, 77, 755-776. [CrossRef]

23. Nunoshiba, T.; Hidalgo, E.; Cuevas, C.F.A.; Demple, B. Two-stage control of an oxidative stress regulon: The Escherichia coli SoxR protein triggers redox-inducible expression of the soxS regulatory gene. J. Bacteriol. 1992, 174, 6054-6060. [CrossRef] [PubMed]

24. Seo, S.W.; Kim, D.; Szubin, R.; Palsson, B.O. Genome-wide Reconstruction of OxyR and SoxRS Transcriptional Regulatory Networks under Oxidative Stress in Escherichia coli K-12 MG1655. Cell Rep. 2015, 12, 1289-1299. [CrossRef]

25. Erental, A.; Sharon, I.; Engelberg-Kulka, H. Two Programmed Cell Death Systems in Escherichia coli: An Apoptotic-Like Death Is Inhibited by the mazEF Mediated Death Pathway. PLoS Biol. 2012, 10, e1001281. [CrossRef]

26. Erental, A.; Kalderon, Z.; Saada, A.; Smith, Y.; Engelberg-Kulka, H. Apoptosis-Like Death, an Extreme SOS Response in Escherichia coli. mBio 2014, 5, e01426-14. [CrossRef]

27. Noor, R.; Murata, M.; Yamada, M. Oxidative Stress as a Trigger for Growth Phase-Specific oE-Dependent Cell Lysis in Escherichia coli. J. Mol. Microbiol. Biotechnol. 2009, 17, 177-187. [CrossRef] [PubMed]

28. Mendonca, V.M.; Kaiser-Rogers, K.; Matson, S.W. Double helicase II (uvrD)-helicase IV (helD) deletion mutants are defective in the recombination pathways of Escherichia coli. J. Bacteriol. 1993, 175, 4641-4651. [CrossRef] [PubMed]

29. Tenorio, E.; Saeki, T.; Fujita, K.; Kitakawa, M.; Baba, T.; Mori, H.; Isono, K. Systematic characterization of Escherichia coli genes/ORFs affecting biofilm formation. FEMS Microbiol. Lett. 2003, 225, 107-114. [CrossRef]

30. Sutterlin, H.A.; Shi, H.; May, K.L.; Miguel, A.; Khare, S.; Huang, K.C.; Silhavy, T.J. Disruption of lipid homeostasis in the Gram-negative cell envelope activates a novel cell death pathway. Proc. Natl. Acad. Sci. USA 2016, 113, E1565-E1574. [CrossRef] [PubMed]

31. Schakermann, M.; Langklotz, S.; Narberhaus, F. FtsH-Mediated Coordination of Lipopolysaccharide Biosynthesis in Escherichia coli Correlates with the Growth Rate and the Alarmone (p)ppGpp. J. Bacteriol. 2013, 195, 1912-1919. [CrossRef] [PubMed] 
32. Biernacka, D.; Gorzelak, P.; Klein, G.; Raina, S. Regulation of the First Committed Step in Lipopolysaccharide Biosynthesis Catalyzed by LpxC Requires the Essential Protein LapC (YejM) and HslVU Protease. Int. J. Mol. Sci. 2020, 21, 9088. [CrossRef] [PubMed]

33. Ogura, T.; Inoue, K.; Tatsuta, T.; Suzaki, T.; Karata, K.; Young, K.; Su, L.-H.; Fierke, C.A.; Jackman, J.E.; Raetz, C.R.H.; et al Balanced biosynthesis of major membrane components through regulated degradation of the committed enzyme of lipid A biosynthesis by the AAA protease FtsH (HflB) in Escherichia coli. Mol. Microbiol. 1999, 31, 833-844. [CrossRef] [PubMed]

34. Führer, F.; Langklotz, S.; Narberhaus, F. The C-terminal end of LpxC is required for degradation by the FtsH protease. Mol. Microbiol. 2006, 59, 1025-1036. [CrossRef] [PubMed]

35. Hassan, H.M.; Sun, H.C. Regulatory roles of Fnr, Fur, and Arc in expression of manganese-containing superoxide dismutase in Escherichia coli. Proc. Natl. Acad. Sci. USA 1992, 89, 3217-3221. [CrossRef]

36. Jain, K.; Saini, S. MarRA, SoxSR, and Rob encode a signal dependent regulatory network in Escherichia coli. Mol. BioSyst. 2016, 12, 1901-1912. [CrossRef]

37. Baba, T.; Ara, T.; Hasegawa, M.; Takai, Y.; Okumura, Y.; Baba, M.; Datsenko, K.A.; Tomita, M.; Wanner, B.L.; Mori, H. Construction of Escherichia coli K-12 in-frame, single-gene knockout mutants: The Keio collection. Mol. Syst. Biol. 2006, 2. [CrossRef]

38. Kabir, S.; Sagara, T.; Oshima, T.; Kawagoe, Y.; Mori, H.; Tsunedomi, R.; Yamada, M. Effects of mutations in the rpoS gene on cell viability and global gene expression under nitrogen starvation in Escherichia coli. Microbiology 2004, 150, 2543-2553. [CrossRef]

39. Miller, J.H. A Short Course in Bacterial Genetics: A Laboratory Manual and Handbook for Escherichia coli and Related Bacteria; Cold Spring Harbor Laboratory Press: New York, NY, USA, 1992.

40. Datsenko, K.A.; Wanner, B.L. One-step inactivation of chromosomal genes in Escherichia coli K-12 using PCR products. Proc. Natl. Acad. Sci. USA 2000, 97, 6640-6645. [CrossRef]

41. Kitagawa, M.; Ara, T.; Arifuzzaman, M.; Ioka-Nakamichi, T.; Inamoto, E.; Toyonaga, H.; Mori, H. Complete set of ORF clones of Escherichia coli ASKA library (A Complete Set of E. coli K-12 ORF Archive): Unique Resources for Biological Research. DNA Res. 2006, 12, 291-299. [CrossRef]

42. Guzman, L.M.; Belin, D.; Carson, M.J.; Beckwith, J. Tight regulation, modulation, and high-level expression by vectors containing the arabinose $\mathrm{P}_{\mathrm{BAD}}$ promoter. J. Bacteriol. 1995, 177, 4121-4130. [CrossRef]

43. Sambrook, J.; Russell, D.W. Molecular Cloning: A Laboratory Manual, 3rd ed.; Cold Spring Harbor Laboratory Press: New York, NY, USA, 2001; Volume 3.

44. Aiba, H.; Adhya, S.; de Crombrugghe, B. Evidence for two functional gal promoters in intact Escherichia coli cells. J. Biol. Chem. 1981, 256, 11905-11910. [CrossRef]

45. Charoensuk, K.; Irie, A.; Lertwattanasakul, N.; Sootsuwan, K.; Thanonkeo, P.; Yamada, M. Physiological Importance of Cytochrome $c$ Peroxidase in Ethanologenic Thermotolerant Zymomonas mobilis. J. Mol. Microbiol. Biotechnol. 2011, $20,70-82$. [CrossRef] [PubMed]

46. Karp, P.D.; Riley, M.; Saier, M.; Paulsen, I.T.; Collado-Vides, J.; Paley, S.M.; Pellegrini-Toole, A.; Bonavides, C.; Gama-Castro, S. The EcoCyc Database. Nucleic Acids Res. 2002, 30, 56-58. [CrossRef]

47. Kanehisa, M.; Goto, S.; Kawashima, S.; Nakaya, A. The KEGG databases at GenomeNet. Nucleic Acids Res. 2002, 30 , 42-46. [CrossRef]

48. Dulley, J.R.; Grieve, P.A. A simple technique for eliminating interference by detergents in the Lowry method of protein determination. Anal. Biochem. 1975, 64, 136-141. [CrossRef] 